\title{
GC-MS as a tool for reliable non-invasive prenatal diagnosis of Smith-Lemli-Opitz syndrome but essential also for other cholesterolopathies verification
}

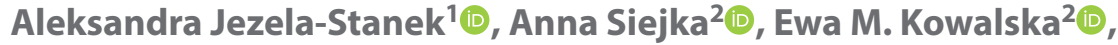 \\ Violetta Hosiawa ${ }^{3}$, Malgorzata Krajewska-Walasek ${ }^{1,4}$ (1) \\ ${ }^{1}$ Department of Genetics and Clinical Immunology, National Institute of Tuberculosis and Lung Diseases, Warsaw, Poland \\ ${ }^{2}$ Department of Biochemistry, Radioimmunology and Experimental Medicine, \\ The Children's Memorial Health Institute, Warsaw, Poland \\ ${ }^{3}$ Department of Gynecologic Oncology, Jagiellonian University Medical College, Cracow, Poland \\ ${ }^{4}$ Department of Medical Genetics, The Children's Memorial Health Institute, Warsaw, Poland
}

\begin{abstract}
Rare multiple congenital malformations/developmental disorders are challenging in clinical diagnosis. The introduction of next-generation sequencing (NGS) has revolutionized this diagnostic by offering multigene panels or whole-exome sequencing. However, if there is no possibility to perform NGS or if we are facing prenatal ultrasound results, clinical diagnostics is even more difficult. For a selected group of congenital metabolic disorders, resulting from defects in cholesterol biosynthesis (called cholesterolopathies), application of gas chromatography-mass spectrometry (GS-MS) may provide or orientate diagnostics. The most common of these is Smith-Lemli-Opitz syndrome (SLOS), but in this publication, we also want to introduce other cholesterolopathies and draw attention to the possibility of non-invasive prenatal diagnosis of SLOS.

Key words: prenatal diagnosis; GC-MS; prenatal ultrasound; Smith-Lemli-Opitz; cholesterol biosynthesis
\end{abstract}

Ginekologia Polska 2020; 91, 5: 287-293

\section{INTRODUCTION}

Cholesterol (cholest-5-en-3beta-ol) is a chemical compound belonging to specific lipids called steroids, which common feature is the presence of a carbon skeleton, composed of four coupled rings (steran) (Fig. 1).

In the human body, it occurs in plasma, blood and tissues in both free and fatty acid esterified forms. Endogenous cholesterol is mainly synthesized in the liver, intestines and

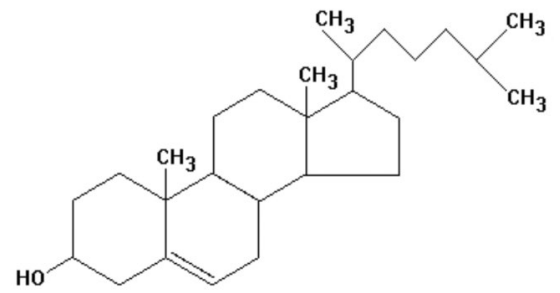

Figure 1. Cholesterol $\left(\mathrm{C}_{27} \mathrm{H}_{46} \mathrm{O}\right)$ with marked side groups (hydroxyl and methyl) skin, as well as in the central nervous system [1]. The human brain contains $23 \%$ of the cholesterol circulating in the body. Most of it is synthesized in oligodendrocytes and accumulated in myelinated axon sheaths, but it is also found in the cells of neurons and astrocytes. The blood-brain barrier prevents the penetration of cholesterol from the bloodstream, which excludes the regulation of cholesterol levels in the brain through supplementation [1]. The optimal amount of cholesterol in the human body is determined by the correct course of the process of its biosynthesis, which may be disturbed in discussed below syndromes.

Although the developing fetus attempts to synthesize cholesterol, in the first weeks of pregnancy, it uses mainly maternal cholesterol. Its transport through the membranes of the secondary yolk sac (during the first eight weeks of gestation), and later the placenta (when trophoblast takes over its nutritional role) to the fetal circulation, determines the proper development of the embryo and 


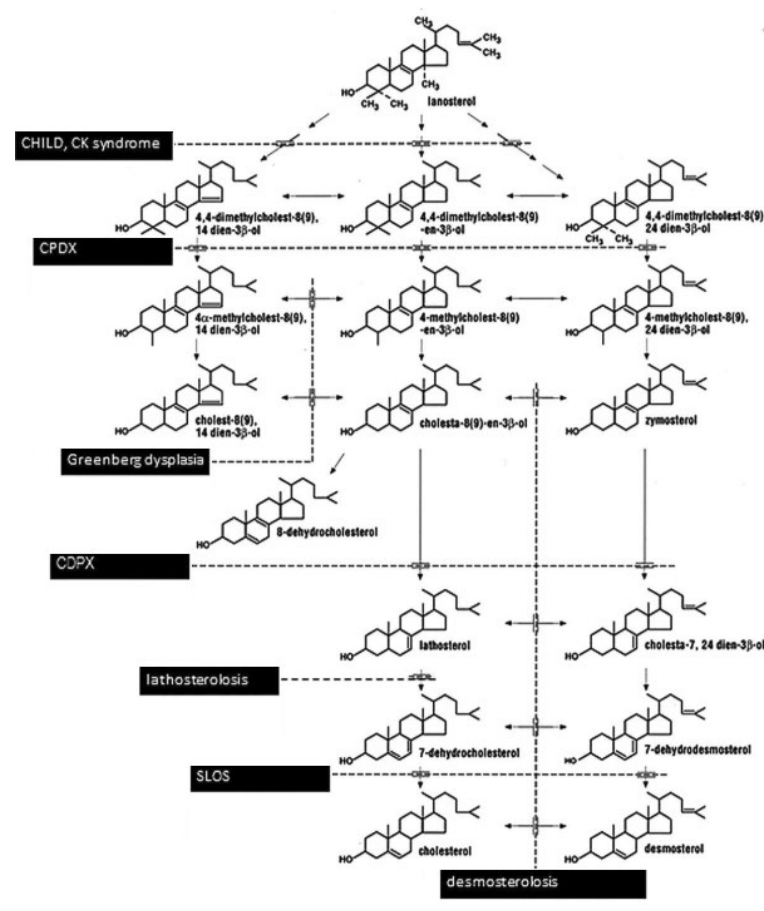

Figure 2. Part of the cholesterol biosynthesis pathway (modified from Nowaczyk MJM, Cunniff C. 2012. Smith-Lemli-Opitz syndrome and other disorders of cholesterol biosynthesis: An introduction. Am J Med Genet Part C Semin Med Genet 160C: 239-241).

the development of most organs. Cholesterol molecules collected by the embryo participate in signalling pathways crucial for embryonic development - they regulate the function of sonic hedgehog $(\mathrm{SHH})$ proteins [2]. These proteins determine the survival and migration of nerve cells and important nuclear receptors, such as the transcription factor for alpha-fetoprotein, which, by binding to DNA GATA sequences, enables the transcription of numerous genes involved in the development of crucial organs [3].

Congenital defects in enzymes of the cholesterol biosynthesis pathway have recently emerged as significant causes of congenital anomalies. Patients with these metabolic diseases present with different malformations that involve many organs and systems [4-6]. To date, nine disorders due to enzymatic defects in post-squalene cholesterol biosynthesis have been identified (Fig. 2). These are:

1. Smith-Lemli-Opitz syndrome (SLOS, OMIM: 270400),

2. X-linked dominant chondrodysplasia punctata type 2 (CDPX2, OMIM: 302960) and MEND (male EBP disorder with neurological defects; OMIM: 300960),

3. Congenital hemidysplasia with ichthyosiform erythroderma and limb defects syndrome (CHILD syndrome, OMIM: 308050),

4. Sterol-C4-methyloxidase-like deficiency (SC4MOL deficiency, OMIM: 607545),

5. CK syndrome [named for the initials of the original proband] (OMIM: 300831),
6. Greenberg/HEM dysplasia (hydrops-ectopic calcification-moth-eaten skeletal dysplasia, OMIM: 215140), (this phenotype is likely due to a laminopathy, but is usually discussed with inborn errors of cholesterol synthesis, see Table 1 for causative details),

7. Antley-Bixler syndrome with ambiguous genitalia (cytochrome P450 oxidoreductase deficiency, POR deficiency, OMIM: 201750),

8. Desmosterolosis (OMIM: 602398),

9. Lathosterolosis (OMIM: 607330).

\section{SMITH-LEMLI-OPITZ SYNDROME}

The best-known among the listed diseases is Smith-Lemli-Opitz syndrome caused by a low activity of $3 \beta$-hydroxysteroid-D7-reductase (7-dehydrocholesterol reductase, DHCR7). Its role is to convert 7-dehydrocholesterol (7DHC) into cholesterol in the Kandutsch-Russell pathway and 7-dehydrodesmosterol into desmosterol in the Bloch pathway (Fig. 3).

Desmosterol is mainly present in the brain [7]. SLOS, first described in 1964, is also the first multiple malformation syndrome attributed to an inborn error of sterol synthesis $[8,9]$. The consequence of a malfunctioning enzyme is primarily the accumulation of 7-DHC in blood and tissue and probably 7-dehydrodesmosterol in the brain [10]. Besides, acting in cells $\Delta 7, \Delta 8$-isomerase converts 7-dehydrocholesterol into 8-dehydrocholesterol, and ,similarly, 7-dehydrodesmosterol in 8-dehydrodesmosterol) [11]. Studies have shown that patients with milder symptoms have normal cholesterol levels in the membranes of nerve cells, which is probably due to its local synthesis. At the same time, it seems that disease symptoms may also be caused by the accumulation of 7,8-dehydrodesmosterol or its oxidised metabolites [10].

Although its clinical presentation may vary, SLOS is usually characterized by prenatal and postnatal growth retardation, microcephaly, moderate to severe intellectual disability, and multiple major and minor malformations, including characteristic facial features, cleft palate, cardiac defects, postaxial polydactyly, 2-3 toe syndactyly, hypospadias, and undervirilization of the genitalia in males $[9,12$, personal observation]. There are also data suggesting higher intrauterine mortality of SLOS-affected fetuses [13]. The reported manifestations of Smith-Lemli-Opitz syndrome during the prenatal period (presented in Tab. 1) include, among others: intrauterine growth retardation $[14,15]$, low maternal unconjugated estriol (MSuE3) [16], or a combination of very rare congenital anomalies, such as ulnar hypoplasia, vertebral segmentation anomalies, congenital pulmonary adenomatoid malformation, fused lungs, laparoschisis, holomyelia, and hypothalamic hamartoma [17]. 


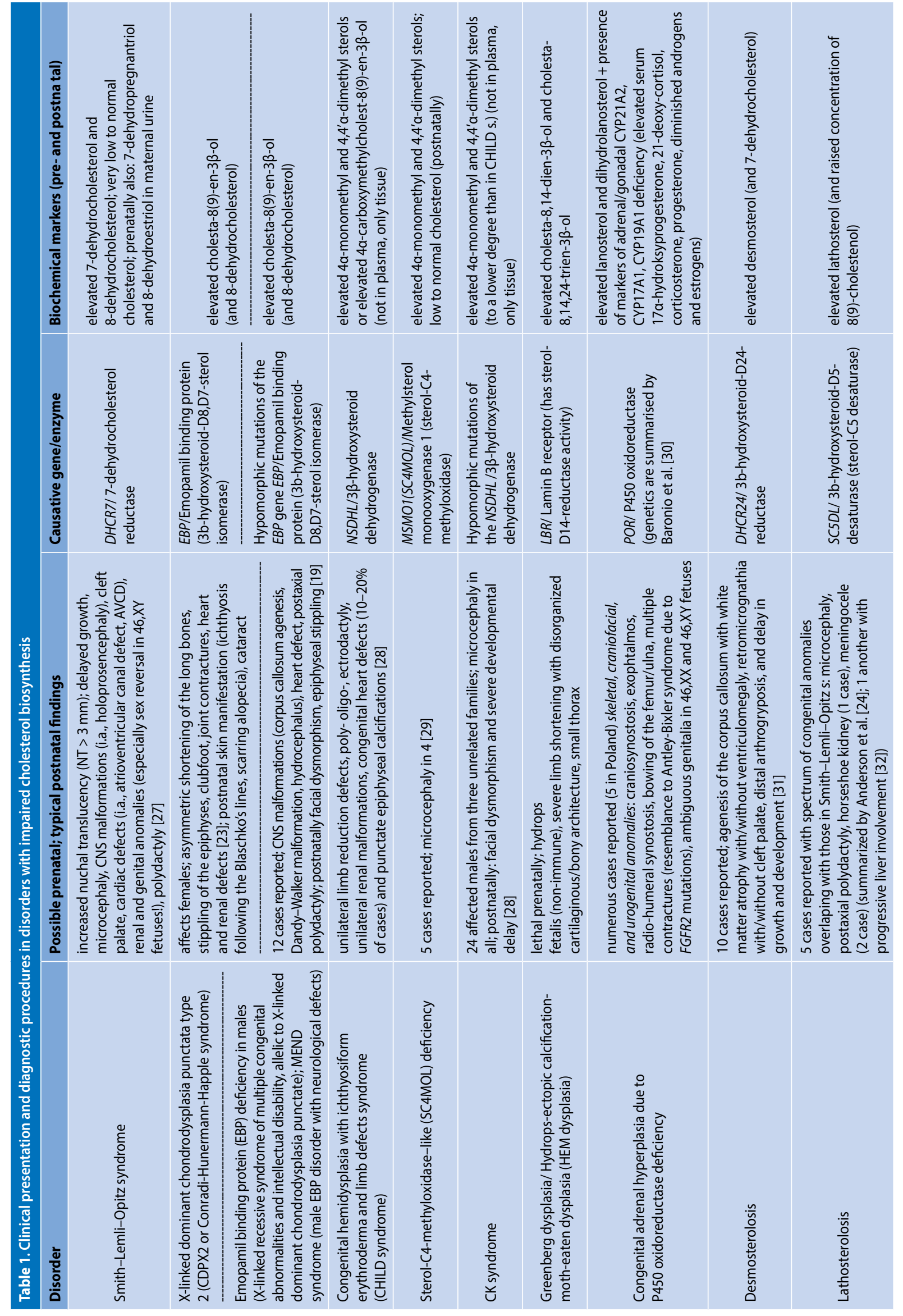




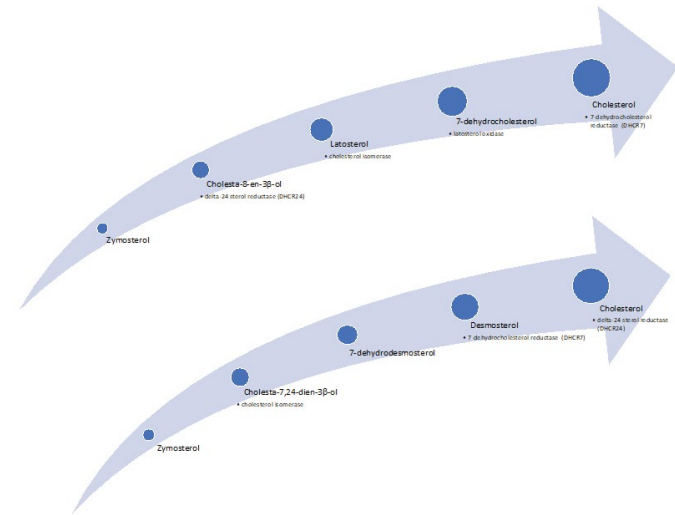

Figure 3. Graphs showing two ways of cholesterol biosynthesis and the most important metabolites of the Kandutsch-Russell (above) and Bloch (below) pathways. Involved enzymes are under the name of a chemical compound

\section{PRENATAL FINDINGS AND POSTNATAL PRESENTATION OF INBORN ERRORS OF CHOLESTEROL BIOSYNTHESIS}

Except for Smith-Lemli-Opitz syndrome, other diseases with aberrant cholesterol biosynthesis are rarely diagnosed. Some of them, however, show phenotypic overlap with SLOS, e.g., lathosterolosis [18] or emopamil binding protein (EBP) deficiency in males [19]. Other disorders, e.g., HEM dysplasia, CHILD syndrome, or POR deficiency, may result in specific and somehow recognizable prenatal findings (as noted in Table 1). Since the detailed descriptions of the syndromes mentioned above caused by congenital cholesterol biosynthesis defects have already been discussed in several publications $[4,5,20-23]$ reiterating imaging findings in details here is beyond the scope of this manuscript. In Table 1 we listed most significant clinical and detailed biochemical features that are indicative of specific syndromes caused by an inborn error in cholesterol biosynthesis, thus being helpful in prenatal evaluation of fetuses with specific developmental anomalies.

Therefore, we believe that it is worth keeping this group of disorders in mind during prenatal evaluation. It allows ordering the proper biochemical and/or molecular diagnostic tests to establish the diagnosis, verify the carrier status in the couples, specifying the recurrence risk in subsequent pregnancies in the family, as well as implementing adequate support for the child: with a high-cholesterol diet in Smith-Lemli-Opitz syndrome or, as reported just recently, with simvastatin in lathosterolosis [24] as soon as possible. For most rare diseases, including inborn errors of metabolism, before attempting to perform prenatal testing in at-risk families, it is essential to establish the diagnosis in the affected relatives or carrier status in the couples. Nevertheless, as congenital errors of cholesterol biosynthesis may be associated with: a) abnormal ultrasound features (mentioned in Tab. 1), b) a gestational biochemical marker (such as low maternal serum unconjugated estriol, $\mathrm{uE}_{3}$; abnormal GC-MS results) it is possible, although challenging, to suspect such disorders in the course of a pregnancy, even without a previous index case in the family $[18,26]$.

\section{LABORATORY DIAGNOSTICS OF INBORN ERRORS OF CHOLESTEROL BIOSYNTHESIS}

Cholesterol precursors are specific biochemical markers of its biosynthesis. Hence their quantification in body fluids, amniotic fluid samples or tissues is useful for the diagnosis of cholesterol biosynthesis pathway disorders. The proper prenatal diagnosis of these syndromes is of great value both for the given family (giving a reliable recurrence risk and the possibility to perform prenatal or preimplantation diagnostics) and for scientific studies (by improving current knowledge on human developmental processes).

A rapid and reliable diagnosis may be established using gas chromatography-mass spectrometry (GC-MS). It has been developed and validated for quantitative analysis of five sterols: cholesterol, 7-dehydrocholesterol, desmosterol, lathosterol, and sitosterol in amniotic fluid and plasma [19]. Moreover, reliable prenatal diagnosis of Smith-Lemli-Opitz syndrome may be achieved in a rapid and non-invasive manner by GC-MS analysis of a maternal urine sample [33, 34]. It is based on measurements of specific metabolites, 7-dehydropregnantriol and 8-dehydroestriol, that are definite markers for pregnancies with SLOS-affected fetuses. It is noteworthy that Smith-Lemli-Opitz syndrome is the only autosomal recessive (with $25 \%$ risk of recurrence), multiple congenital anomaly disorder where such (urine-based, biochemical) non-invasive and reliable prenatal diagnosis is available.

Years ago, Department of Biochemistry at $\mathrm{CMHI}$ introduced three methods of analysis of SLOS-specific 7- and 8-dehydrometabolites that detect their abnormal concentrations of fetal origin in pregnant women in a single sample of mother's urine, in amniotic fluid and after birth in the child's blood. The first one, as a non-invasive procedure, is clinically very attractive and of great practical value (personal observation). During the analysis the excretion of 7 and 8-dehydropregnanetriol (7-,8-DHPT), pregnantriol (PT), pregnandiol (PD), estriol (E3) and 8-dehydroestriol (8-DHE3) is measured. In the urine of pregnant mothers, high excretion of 7- and 8-DHPT is observed in fetuses affected by SLOS [33] (Fig. 4).

However, the highest diagnostic value of pregnancy affected by SLO syndrome is found in the 7-DHPT/PT and (8-DHE3)/E3 ratios [35]. Increased amounts of 7- and 8-dehydrometabolites of fetal steroid origin expressed in relation to naturally occurring estriol and pregnanetriol in the pregnant mother's urine is a biochemical indicator of a genetic defect 


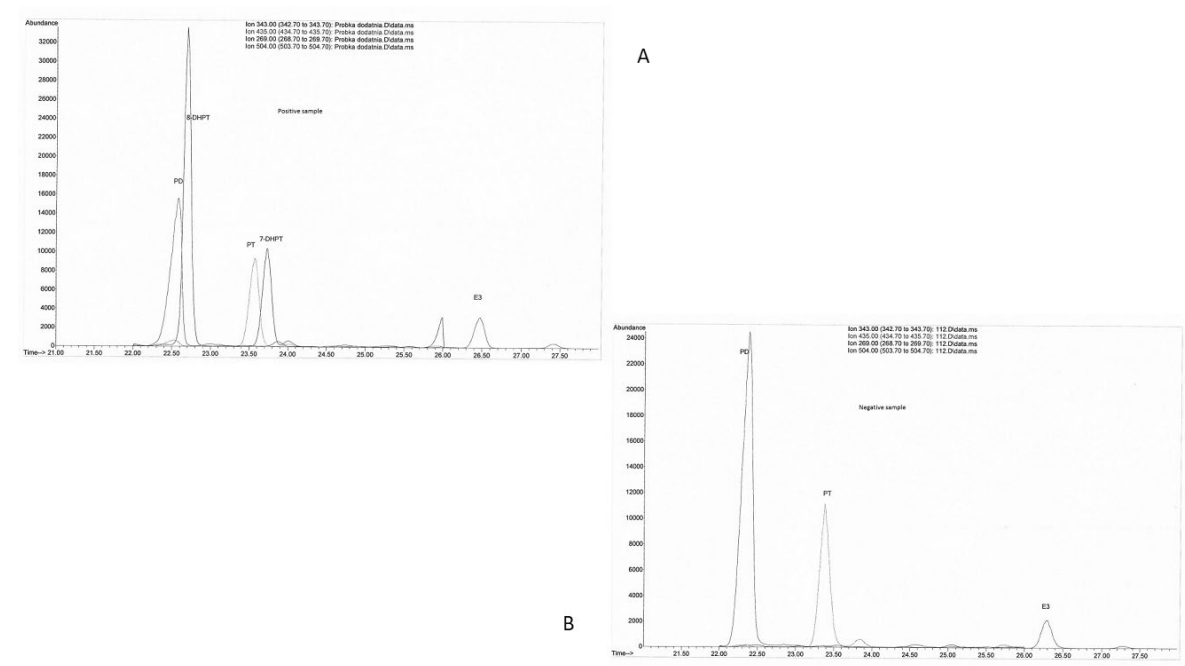

Figure 4. GC/MS results of maternal urine sample in pregnancy; A. affected with Smith-Lemli-Opitz syndrome (note elevated 7- and 8-DHPT); B. healthy child

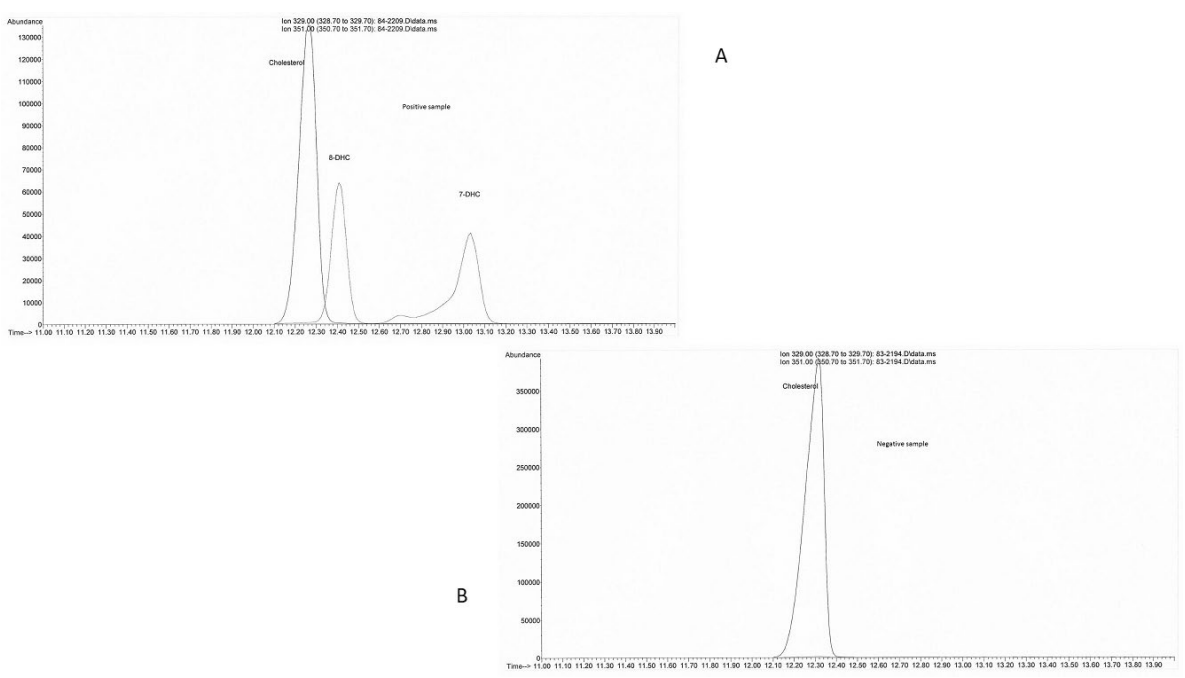

Figure 5. GC/MS of plasma sample from; A. patient affected with Smith-Lemli-Opitz syndrome (note elevated 7- and 8-DHC); B. healthy patients

in the $D H C R 7$ gene in the fetus. Morning urine samples of pregnant women taken between 13 and 24 weeks of gestation are preferred for analysis.

Another technique to detect DHCR7 deficiency in the fetus is the analysis of amniotic fluid metabolites, where 7- and 8-dehydrocholesterol occurring in trace amounts in children without SLO syndrome are directly quantified. The same chemical compounds are determined in the child's plasma after birth, and their concentration is $50-1000$ times higher than the reference norm, which at low cholesterol is a high diagnostic value in SLO syndrome (Fig. 5).

For verification of biochemical results or in cases when prenatal samples are not useful for biochemical tests (borderline normal results or lack of validation for specific markers), molecular analyses may be offered for prenatal detection of the discussed syndromes. They are based on DNA isolated from chorionic villus, amniotic fluid or rarely umbilical blood. Results of biochemical analysis of maternal urine, amniotic fluid and direct CVS analysis are available within 2 or 3 days. Molecular studies of cultured amniocytes or villus cells require 2 to 3 weeks to complete.

\section{CONCLUSIONS}

We hope that this article will provide readers with knowledge about a group of disorders characterized by defects in cholesterol biosynthesis, thus increasing awareness in the medical community about their diagnosis, especially in the prenatal period with the application of non-invasive prenatal biochemical test (GC-MS analysis). The validated methodology allows for cheap (comparing to molecular 
Table 2. Details concerning samples and shipment for testing toward Smith-Lemli-Opitz syndrome to the CMHI

\begin{tabular}{l|l|l|l|}
\hline SLOS markers/material & Sample requirements & Necessary forms \\
\hline $\begin{array}{l}\text { 7,8-dehydro-cholesterol and cholesterol in } \\
\text { amniotic fluid (AF); also latosterol, desmosterol } \\
\text { (in 13-18 hbd samples) }\end{array}$ & $1 \mathrm{ml} \mathrm{AF}$ & $\begin{array}{l}\text { protect the tube from } \\
\text { sunlight, wrap with dark } \\
\text { film }\end{array}$ & $\begin{array}{l}\text { Test Requisition Form available at: } \\
\text { ww.czd.pl (refer to Pracownia Hormonów } \\
\text { Steroidowych i Zaburzeń Metabolizmu) }\end{array}$ \\
\hline $\begin{array}{l}\text { estriol, 8-dehydroestriol, 7-dehydropregnantriol, } \\
\text { pregnantriol, pregnandiol in maternal } \\
\text { urine + creatinine }\end{array}$ & $\begin{array}{l}\text { single morning urine } \\
\text { sample of pregnant } \\
\text { women } \geq 13 \mathrm{hbd}\end{array}$ & as above & as above \\
\end{tabular}

testing, including a panel of genes or exome sequencing), fast and reliable diagnosis of some of them. In Poland, it is offered at the Children's Memorial Health Institute, Department of Biochemistry, Radioimmunology and Experimental Medicine. The details of samples and shipment for Smith-Lemli-Opitz syndrome testing are given in the table below.

\section{Funding}

None.

\section{Conflict of interest}

None.

\section{REFERENCES}

1. MillerW, Bose H. Early steps in steroidogenesis: intracellular cholesterol trafficking. Journal of Lipid Research. 2011; 52(12): 2111-2135, doi: 10.1194/jIr.r016675.

2. Wolf $\mathrm{G}$. The function of cholesterol in embryogenesis. J Nutr Biochem. 1999; 10(4): 188-192, doi: 10.1016/s0955-2863(98)00102-8, indexed in Pubmed: 15539288.

3. Baardman ME, Kerstjens-FrederikseWS, Berger RMF, et al. The role of maternal-fetal cholesterol transport in early fetal life: current insights. Biol Reprod. 2013; 88(1): 24, doi: 10.1095/biolreprod.112.102442, indexed in Pubmed: 23153566.

4. Porter FD, Herman GE. Malformation syndromes caused by disorders of cholesterol synthesis. J Lipid Res. 2011; 52(1): 6-34, doi: 10.1194/jlr. R009548, indexed in Pubmed: 20929975.

5. Herman GE, Kratz L. Disorders of sterol synthesis: beyond Smith-Lemli-Opitz syndrome. Am J Med Genet C Semin Med Genet. 2012; 160C(4): 301-321, doi: 10.1002/ajmg.c.31340, indexed in Pubmed: 23042573.

6. Nowaczyk MJM, Cunniff C. Smith-Lemli-Opitz syndrome and other disorders of cholesterol biosynthesis: An introduction. Am J Med Genet C Semin Med Genet. 2012; 160C(4): 239-241, doi: 10.1002/ajmg.c.31344, indexed in Pubmed: 23042602.

7. DeBarber AE, Eroglu Y, Merkens LS, et al. Smith-Lemli-Opitz syndrome. Expert Rev Mol Med. 2011; 13: e24, doi: 10.1017/S146239941100189X, indexed in Pubmed: 21777499.

8. SMITH DW, LEMLI L, OPITZ JM. A NEWLY RECOGNIZED SYNDROME OF MULTIPLE CONGENITAL ANOMALIES. J Pediatr. 1964; 64: 210-217, doi: 10.1016/s0022-3476(64)80264-x, indexed in Pubmed: 14119520.

9. Nowaczyk MJM, Irons MB. Smith-Lemli-Opitz syndrome: phenotype, natural history, and epidemiology. Am J Med Genet C Semin Med Genet. 2012; 160C(4): 250-262, doi: 10.1002/ajmg.c.31343, indexed in Pubmed: 23059950.

10. Martín MG, Pfrieger F, Dotti CG. Cholesterol in brain disease: sometimes determinant and frequently implicated. EMBO Rep. 2014; 15(10): 10361052, doi: 10.15252/embr.201439225, indexed in Pubmed: 25223281.

11. Batta AK, Salen G, Tint GS, et al. Identification of 8-dehydrocholesterol (cholesta-5,8-dien-3 beta-ol) in patients with Smith-Lemli-Opitz syndrome. J Lipid Res. 1995; 36(4): 705-713, indexed in Pubmed: 7616117.

12. Porter FD. Smith-Lemli-Opitz syndrome: pathogenesis, diagnosis and management. Eur J Hum Genet. 2008; 16(5): 535-541, doi: 10.1038/ejhg.2008.10, indexed in Pubmed: 18285838.
13. Jezela-Stanek A, Ciara E, Małunowicz E, et al. Smith-Lemli-Opitz syndrome Collaborative Group. Differences between predicted and established diagnoses of Smith-Lemli-Opitz syndrome in the Polish population: underdiagnosis or loss of affected fetuses? J Inherit Metab Dis. 2010; 33 Suppl 3: S241-S248, doi: 10.1007/s10545-010-9132-4, indexed in Pubmed: 20556518.

14. Goldenberg A, Wolf $C$, Chevy F, et al. Antenatal manifestations of Smith-Lemli-Opitz (RSH) syndrome: a retrospective survey of 30 cases. Am J Med Genet A. 2004; 124A(4): 423-426, doi: 10.1002/ajmg.a.20448, indexed in Pubmed: 14735596.

15. Haas D, Haege G, Hoffmann GF, et al. Prenatal presentation and diag nostic evaluation of suspected Smith-Lemli-Opitz (RSH) syndrome. Am J Med Genet A. 2013; 161A(5): 1008-1011, doi: 10.1002/ajmg.a.35837, indexed in Pubmed: 23532938.

16. Shinawi M, Szabo S, Popek E, et al. Recognition of Smith-Lemli-Opitz syndrome (RSH) in the fetus: utility of ultrasonography and biochemical analysis in pregnancies with low maternal serum estriol. Am J Med Genet A. 2005; 138(1): 56-60, doi: 10.1002/ajmg.a.30898, indexed in Pubmed: 16097001

17. Quélin $C$, Loget $P$, Verloes $A$, et al. Phenotypic spectrum of fetal Smith-Lemli-Opitz syndrome. Eur J Med Genet. 2012; 55(2): 81-90, doi: 10.1016/j.ejmg.2011.12.002, indexed in Pubmed: 22226660.

18. Ho ACC, Fung CW, Siu TS, et al. Lathosterolosis: a disorder of cholesterol biosynthesis resembling smith-lemli-opitz syndrome. JIMD Rep. 2014; 12: 129-134, doi: 10.1007/8904_2013_255, indexed in Pubmed: 24142275.

19. Rossi M, Hall CM, Bouvier R, et al. Radiographic features of the skeleton in disorders of post-squalene cholesterol biosynthesis. Pediatr Radiol. 2015; 45(7): 965-976, doi: 10.1007/s00247-014-3257-9, indexed in Pubmed: 25646736.

20. Amaral C, Gallardo E, Rodrigues R, et al. Quantitative analysis of five sterols in amniotic fluid by GC-MS: application to the diagnosis of cholesterol biosynthesis defects. J Chromatogr B Analyt Technol Biomed Life Sci. 2010; 878(23): 2130-2136, doi: 10.1016/j.jchromb.2010.06.010, indexed in Pubmed: 20630811.

21. Jira P. Cholesterol metabolism deficiency. Handb Clin Neurol. 2013; 113: 1845-1850, doi: 10.1016/B978-0-444-59565-2.00054-X, indexed in Pubmed: 23622407.

22. Kanungo S, Soares N, He M, et al. Sterol metabolism disorders and neurodevelopment-an update. Dev Disabil Res Rev. 2013; 17(3): 197-210, doi: 10.1002/ddrr.1114, indexed in Pubmed: 23798009.

23. Guibaud L, Collardeau-Frachon S, Lacalm A, et al. Antenatal manifestations of inborn errors of metabolism: prenatal imaging findings. J Inherit Metab Dis. 2017; 40(1): 103-112, doi: 10.1007/s10545-016-9992-3, indexed in Pubmed: 27853988.

24. Anderson R, Rust S, Ashworth J, et al. Lathosterolosis: A Relatively Mild Case with Cataracts and Learning Difficulties. JIMD Rep. 2019; 44: 79-84, doi: 10.1007/8904_2018_127, indexed in Pubmed: 30097991.

25. Whittock NV, Izatt L, Simpson-Dent SL, et al. Molecular prenatal diagnosis in a case of an X-linked dominant chondrodysplasia punctata. Prenat Diagn. 2003; 23(9): 701-704, doi: 10.1002/pd.667, indexed in Pubmed: 12975777.

26. Konstantinidou A, Karadimas C, Waterham HR, et al. Pathologic, radiographic and molecular findings in three fetuses diagnosed with HEM/Greenberg skeletal dysplasia. Prenat Diagn. 2008; 28(4): 309-312, doi: 10.1002/pd.1976, indexed in Pubmed: 18382993.

27. Jezela-Stanek A, Małunowicz E, Anna S, et al.Trends in prenatal diagnosis of non-specific multiple malformations disorders with reference to the own experience and research study on Smith-Lemli-Opitz syndrome. Ginekol Pol. 2015; 86(8): 598-602, doi: 10.17772/gp/57851, indexed in Pubmed: 26492708. 
28. du Souich C, Raymond FL, Grzeschik KH. et al. NSDHL-Related Disorders. 2011 Feb 1 [Updated 2018 Oct 25]. In: Adam MP, Ardinger HH, Pagon RA. et al. ed. GeneReviews ${ }^{\oplus}$. University of Washington, Seattle 1993-2019: [Internet].

29. Frisso G, Gelzo M, Procopio E, et al. A rare case of sterol-C4-methyl oxidase deficiency in a young Italian male: Biochemical and molecular characterization. Mol Genet Metab. 2017; 121(4):329-335, doi: 10.1016/j. ymgme.2017.06.013, indexed in Pubmed: 28673550.

30. Baronio F, Ortolano R, Menabò S, et al. 46,XXDSD due to Androgen Excess in Monogenic Disorders of Steroidogenesis: Genetic, Biochemical, and Clinical Features. Int J Mol Sci. 2019; 20(18), doi: 10.3390/ijms20184605, indexed in Pubmed: 31533357.

31. Rohanizadegan M, Sacharow S. Desmosterolosis presenting with multiple congenital anomalies. Eur J Med Genet. 2018; 61(3): 152-156, doi: 10.1016/j.ejmg.2017.11.009, indexed in Pubmed: 29175559.

32. Prasun $P$, Ferguson E, Iverson A, et al. Lathosterolosis: An Extremely Rare Inherited Condition Associated With Progressive
Liver Disease. J Pediatr Gastroenterol Nutr. 2019; 69(5): e142-e145, doi: 10.1097/MPG.0000000000002434, indexed in Pubmed: 31259789.

33. Shackleton $\mathrm{CH}$, Roitman $\mathrm{E}$, Kratz LE, et al. Midgestational maternal urine steroid markers of fetal Smith-Lemli-Opitz (SLO) syndrome (7-dehydrocholesterol 7-reductase deficiency). Steroids. 1999; 64(7): 446-452, doi: 10.1016/s0039-128x(99)00026-4, indexed in Pubmed: 10443900.

34. Jezela-Stanek A, Małunowicz EM, Ciara E, et al. Maternal urinary steroid profiles in prenatal diagnosis of Smith-Lemli-Opitz syndrome: first patient series comparing biochemical and molecular studies. Clin Genet. 2006; 69(1): 77-85, doi: 10.1111/j.1399-0004.2006.00551.x, indexed in Pubmed: 16451140.

35. Shackleton $\mathrm{CH}$, Roitman $\mathrm{E}$, Kratz L, et al. Dehydro-oestriol and dehydropregnanetriol are candidate analytes for prenatal diagnosis of Smith-Lemli-Opitz syndrome. Prenat Diagn. 2001; 21(3): 207-212, doi: 10.1002/1097-0223(200103)21:3<207::aid-pd27>3.0.co;2-i, indexed in Pubmed: 11260610 . 